\title{
Effect of Different Types of Music on Rosa Chinensis Plants
}

\author{
Vidya Chivukula and Shivaraman Ramaswamy
}

\begin{abstract}
Music influences the growth of plants and can either promote or restrict the growth of plants (depending on the type of music being played). The present experiment is aimed to study the effect of music on 30 Rose (Rosa chinensis) plants taken in separate pots. The plants were divided into five groups and each group was subjected to one of the following types of music, Indian Classical music, Vedic chants, Western Classical music, and Rock music while one group was kept in silence as the control group. The elongation of shoot, internode elongation, the number of flowers and the diameter of the flowers were recorded and changed studied over a period of 60 days. Significant differences have been noted.

It was seen that the plants exposed to Vedic chants showed the maximum elongation of shoot, maximum number of flowers and highest diameter of flowers. The internode elongation was highest in plants exposed to Indian classical music. This clearly shows that the subjecting the plants to Vedic chants or Indian classical music promotes the growth of plants as compared to the control group or subjecting them to Western classical or Rock music.
\end{abstract}

Index Terms-Diameter of flowers, internode length, rosa chinensis, shoot length, music.

\section{INTRODUCTION}

Sound is known to affect the growth of plants [1]. Studies have also shown that sound vibration can be used to stimulate a seed or plant [2]. Previous studies indicate that musical sound has a significant effect on the number of seeds sprouted compared to noise and untreated control and sound vibrations directly affect living biologic systems [1]. Foliage planted along freeways to reduce noise pollution often grows differently than foliage planter in a quiet environment [3], [4]. It would be advantageous for plants to learn about the surrounding environment using sound, as acoustic signals propagate rapidly and detection of sound may have adaptive value in plants [5]. Plants are complex multicellular organisms considered as sensitive as humans for initial assaying of effects and testing new therapies [6]-[8].

Several studies have been undertaken to study and understand the influence of sound and music on plants and plant growth. It has been reported that under optimal stimulation conditions $(100 \mathrm{~dB}$ and $800 \mathrm{~Hz})$ the sound field can enhance the growth of Chrysanthemum callus and moderate stress stimulation can enhance the assimilation of tissues or cells, improve their physiological activity and accelerate the growth of plants [9]. Other studies show that under suitable sound stimulation, the growth of

Manuscript received December 17, 2013; revised February 20, 2014.

Vidya Chivukula is with St. Francis College, Osmania University. Hyderabad, India (e-mail: vidya.0610@gmail.com).
Chrysanthemum roots could be accelerated and the sound stimulation could enhance the metabolism of roots and the growth [10]. Playing appropriate tunes have been found to stimulate the plant's synthesis of its appropriate protein [11]. The rate of water transpired out of leaves is also reportedly affected by sound waves [12] and this in turn affects the growth. Corn plants exposed to music sprouted faster, were greener, and their stems thicker and tougher than the corn plants which were in silence [13] (though these results are not scientifically grounded).

Loud, high frequency, sound tones is known increase the rate of sprouting of alyssum seeds while random noise seems to have the opposite effect [14]. The mechanism is not understood, though it has been noted that the exposure of seedlings and mature plants to green music (classical music and natural sounds such as those of birds, insects, water, etc.) elevates the level of polyamines and increases the uptake of oxygen in comparison with the controls [15]. Reports indicate that plants enjoy music, and they respond to the different types of music and their wave-length. Optimum plant growth occurs when the plant is exposed to pure tones in which the wavelength coincides with the average of major leaf dimensions [16].

Music or sound can also have detrimental effects on plant growth. Some reports indicate that music containing hard-core vibrations could be devastating to plants. Certain types of music can wreak havoc on plants. Even played at a low volume, heavy metal music can be very damaging to a sensitive plant. On the other hand, classical or devotional music enhances the plant growth. Classical music has a gentle vibration, and it's easy on plants. Violin music in particular is known to significantly increases plant growth.

Roses are one of the most popular of flowers in the flowers, with the rose market of US bordering around $\$ 400$ million and production of roses accounting of around 20\% of all flowers across the world. The possibility of improving the rose quantity and quality drives us to experiment with the influence of music on the growth of Rosa chinensis. The objective of the present experiment is to study the effect of different types of music (Indian classical, Vedic chants, Western classical, Rock music) on Rosa chinensis plants.

\section{MATERIALS AND METHODS}

The plant genus used for the experiments was Rose plants. 30 Rosa chinensis plants which were grafted on the same day from a single mother plant were potted in similar sized pots with equal amount of mud containing a uniform mixture of various constituents. They were divided in to five groups with six plants in each group, chosen at random. One of the groups was kept in silence as control group. Each of the other 
four groups was exposed to one of the following types of music, Indian classical music (Violin music of Raaga Sindhu Bhairavi), Vedic chants (Rig Veda), Western classical music (Pachelbel's Canon in D-Soothing) and Rock music (Hate Eternal "Bringer of Storms") for 60 minutes in the morning between 6:00 AM - 7:00 AM, immediately after sun-rise for a period of 62 days. Care was taken to ensure minimal ambient noise and to ensure that the amount of sunlight and water was equal for all the plants.

The length of the shoot was measured everyday using a measuring tape and changes up to a millimeter were noted. The number of flowers was counted on the second day after they bloomed so as to ensure that the flowers bloomed to their fullest. The length of the internode and the diameter of the flowers were measured using a scale.

The analysis was done using the mean of the values of each of the above parameters across the spectrum. Curve fitting was done taking into account the standard deviation of the values. This is to ensure that we were measuring net change averaged across the plants rather than the absolute change of one plant.

\section{RESULTS AND DisCUSSION}

The results (see Table I) show that the average increase of shoot length, number of flowers and diameter of the flowers is highest in plants being subjected to Vedic chants suggesting that the plant growth is enhanced when it is exposed to Vedic chants. The increase in shoot length indicates that the sound of Vedic chants stimulates their growth.

TABLE I: EFFECT OF DifFERENT TYPES OF THE MUSIC ON THE PlANTS, Wherein, A - No. OF Plants, B - Average INCREase IN Plant Height, C - AVERAGE INTERNODE ELONGATION, D - AVERAGE NUMBER OF FLOWERS, E - AVERAGE DIAMETER OF THE FLOWERS

\begin{tabular}{|l|l|l|l|l|l|l|}
\hline No & Music Type & $\mathbf{A}$ & $\mathbf{B}$ (in cm) & $\mathbf{C}$ (in cm) & $\mathbf{D}$ & $\mathbf{E}$ (in cm) \\
\hline 1 & $\begin{array}{l}\text { Indian } \\
\text { classical }\end{array}$ & 6 & 7.334 & 4.000 & 0.598 & 5.376 \\
\hline 2 & Vedic chants & 6 & 7.834 & 3.833 & 0.675 & 5.408 \\
\hline 3 & $\begin{array}{l}\text { Western } \\
\text { classical }\end{array}$ & 6 & 5.251 & 2.183 & 0.525 & 4.690 \\
\hline 4 & Rock & 6 & 3.667 & 1.350 & 0.380 & 3.704 \\
\hline 5 & Silence & 6 & 4.833 & 2.700 & 0.476 & 4.876 \\
\hline
\end{tabular}

The maximum increase of length of the internode is seen in the plants exposed to Indian classical music. Western classical music also stimulates the growth of plants but not as much as Vedic chants and Indian classical music. On the other hand, it is seen that the Rock music stifles the plant growth as the average increase is significantly lower than the rest. In fact, it can be seen that the average growth of the plants subjected to Rock music is also lower that the control set indicating that the vibrations or the sound of Rock music actually has a detrimental effect on the plant growth. This could be because of the plants being unable to take up the required amount of nutrients and some kind of a stasis in protein synthesis' leading to a reduction in growth.

Fig. 1 shows average increase in the shoot length of each plant group. It can be clearly seen that the slope of the plants subjected to Vedic chants (0.1358) is greater than the slope of plants subjected to Indian classical $(0.1217)$ which is greater than the plants subjected to Western classical $(0.0728)$. The control group came in fourth $(0.0675)$ while the growth was minimal in the plants subjected to Rock music (0.0464). The average shoot length of the plants exposed to Vedic chants, Indian classical music, Western classical, control set and Rock music on the 1 st day was $36.583 \mathrm{~cm}, 36.416 \mathrm{~cm}$, $37.916 \mathrm{~cm}, 35 \mathrm{~cm}$, and $36.333 \mathrm{~cm}$ respectively. The average shoot length of the plants on the 62 nd day was $44.417 \mathrm{~cm}$, $43.75 \mathrm{~cm}, 43.167 \mathrm{~cm}, 39.833 \mathrm{~cm}$, and $40 \mathrm{~cm}$ respectively. The increase in the shoot length of the plants is $7.834 \mathrm{~cm}$, $7.334 \mathrm{~cm}, 5.251 \mathrm{~cm}, 4.833 \mathrm{~cm}$, and $3.667 \mathrm{~cm}$ respectively indicating that the rate of increase of the shoot length is the maximum in plants exposed to Vedic chants followed by the plants exposed to Indian classical music, then the plants exposed to Western classical music, the control set and least in the plants exposed to Rock music.

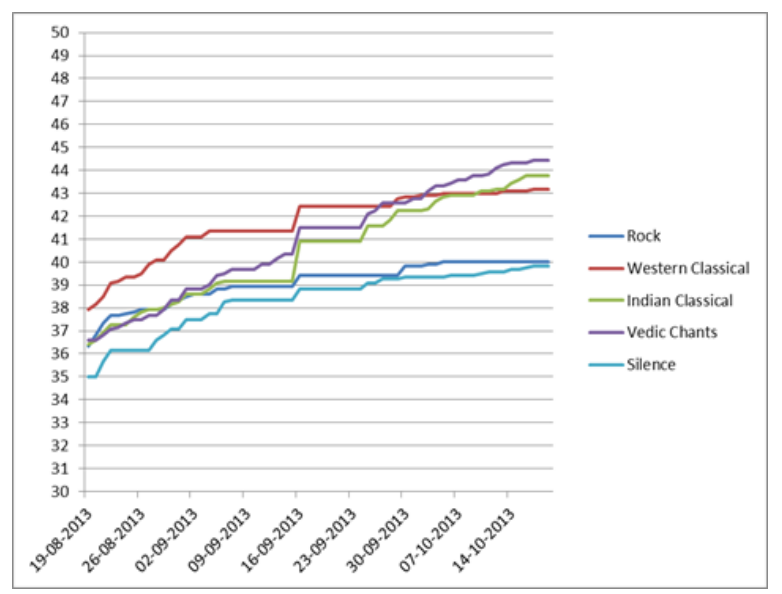

Fig. 1. Graph showing the average rise in shoot length of each plant group.

The average internode length of the plants exposed to Vedic chants, Indian classical music, Western classical, control set and Rock music on the 1 st day was $4.25 \mathrm{~cm}$, $4.417 \mathrm{~cm}, 3.667 \mathrm{~cm}, 5 \mathrm{~cm}$, and $4.833 \mathrm{~cm}$ respectively.

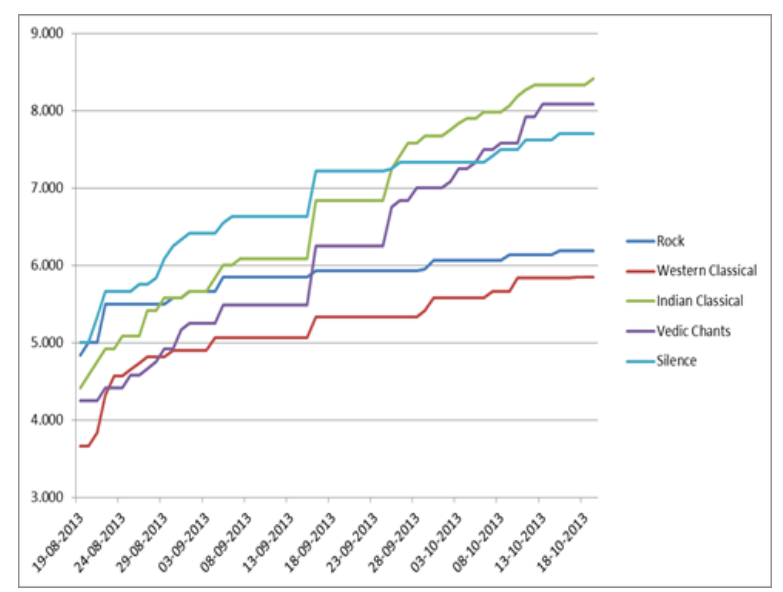

Fig. 2. Graph showing the average increase in inter node distance of each plant group.

Fig. 2, which maps the rate of change of the internode distance across the experimentation period, clearly shows that the slope of plants subjected to Vedic chants $(0.0675)$ is greater than the slope of the plants subjected to Indian classical (0.0654) which is greater than the control group 
(0.038). The end was brought up by Western classical (0.0261) which was still significantly greater than the slop of the plants subjected to Rock music (0.0147).

The average internode length of the plants on the 62 nd day was $8.083 \mathrm{~cm}, 8.417 \mathrm{~cm}, 5.850 \mathrm{~cm}, 7.700 \mathrm{~cm}$, and $6.183 \mathrm{~cm}$ respectively. Thus, the increase in the internode length of the plants is $3.833 \mathrm{~cm}, 4.000 \mathrm{~cm}, 2.183 \mathrm{~cm}, 2.700 \mathrm{~cm}$, and $1.350 \mathrm{~cm}$ respectively indicating that the increase is highest in plants exposed to Indian classical music. But the graph indicates that the slope of increase of internode length of plants exposed to Vedic chants is the most when compared to the rest. This means that though the net change was highest in the Indian classical music, the Vedic chants has the higher rate of change, which would suggest that prolonged experimentation would results in the internode distance of Vedic chants subjected plants being the highest.
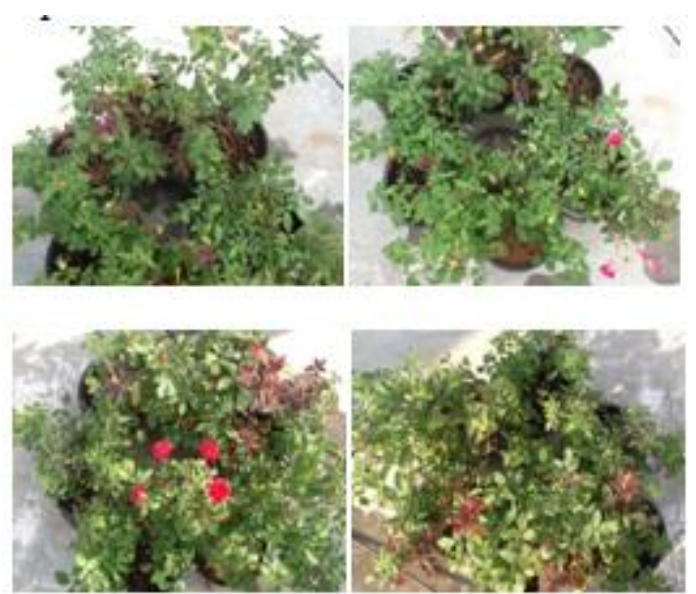

Fig. 3. The growth of Indian classical plants. The plants have completely grown towards the source of the music like positive phototropism. The flowers were pink and normal.

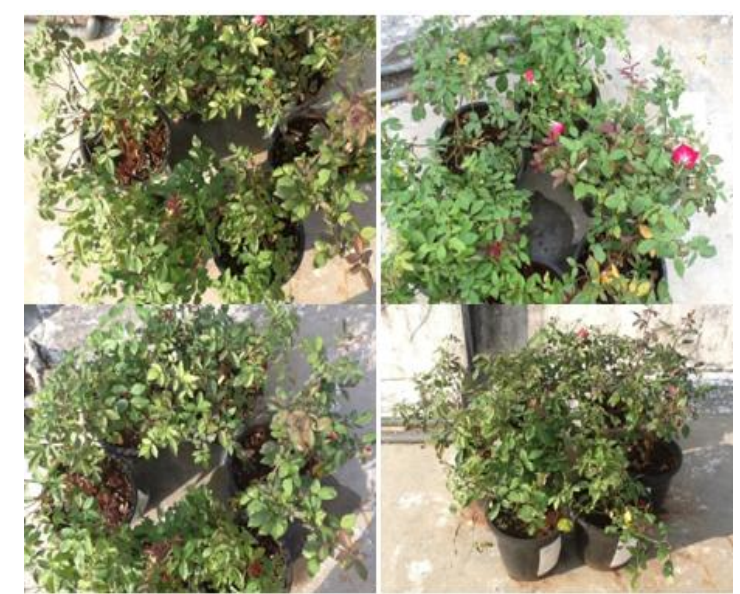

Fig. 4. The growth of Vedic chants plant. Plants are growing in a bushy fashion around the source of music and the flowers are pink.

The next set of results was based on observation of the plants across the period of time. Fig. 3 shows the photographs of the plants subjected to Indian classical music. It was noted that the plants were healthy throughout the experimentation and grew as thick bushes. It was noted that after the third week the branches and bent towards the center (source of music). The leaves were not bent downwards and the number of flowers and their diameter was more than the plants exposed to Western classical music, Rock music and the control set. The flowers were pink and normal.

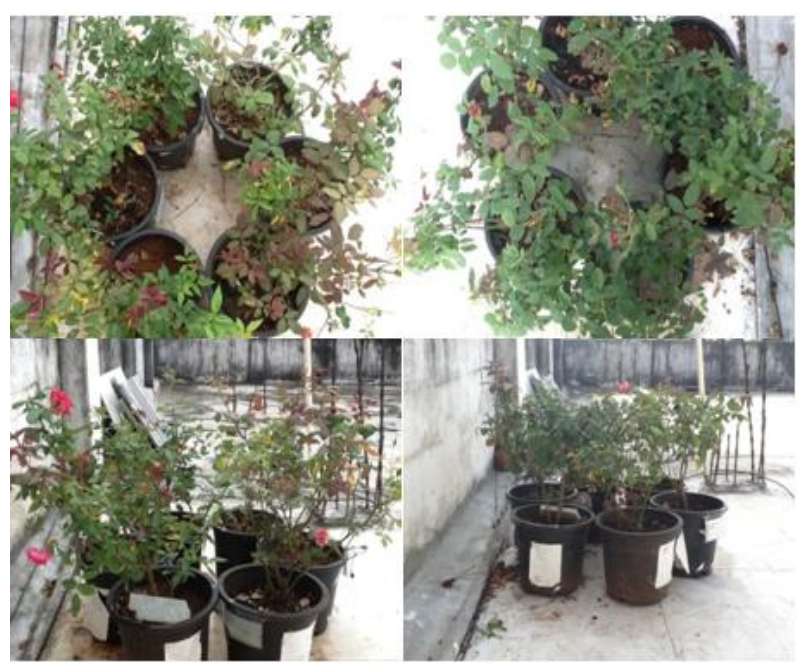

Fig. 5. The plants of Western classical. No significant bending of the plants is seen. The flowers were pink and normal.

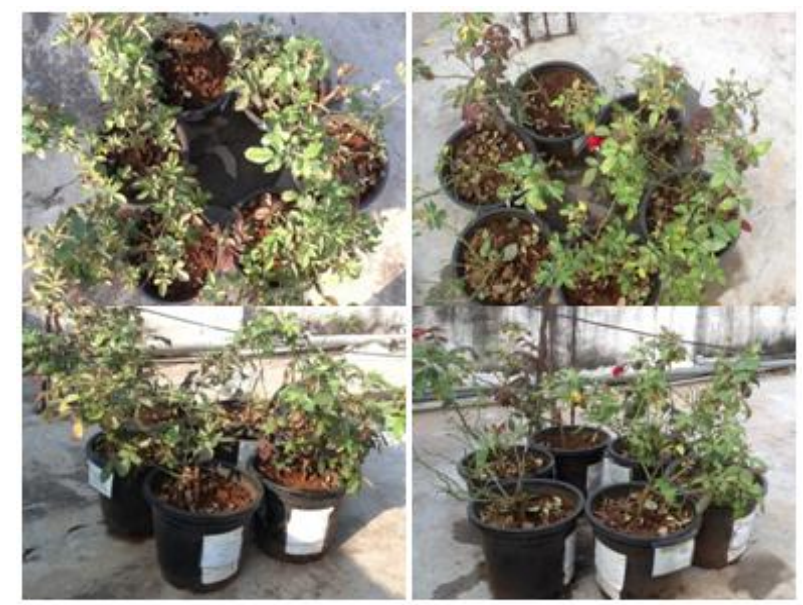

Fig. 6. The plants of Rock music. The number of leaves decreased drastically, the leaves wilted and the plants are growing away from the source of the music. Also, the flowers were deep red in color instead of pink color.

The plants exposed to Vedic chants were seen to growing in a thick bushy fashion around the source of music, Fig. 4. In this case, the plants started bending towards the source of the music towards the end of the second week itself. The leaves density and health of these plants was observably better than the rest of the plants. The number of flowers is highest compared to the other groups indicating that the frequency of flowering is the most in these plants. The flowers were pink and normal. On the other hand, the plants exposed to Western classical music showed no significant difference in the direction of their growth, Fig. 5. They seemed to grow straight up, rather than towards the source of the music. It was noted that the diameter of the flowers and the frequency of flowering are higher than those of the control set, though it was lower than the plants exposed to Vedic chants and Indian classical music.

Contrasting, the plants exposed to Rock music bent away from the source of the music. The number of leaves decreased significantly over the experimentation period and the plants seem dull after 3 weeks, Fig. 6 . The frequency of flowering and the diameter of the flowers was the lowest. The flowers were not pink but were red and significantly smaller in size (the mother plant produced pink flowers). Another important observation was that the plants subjected to Rock music were the first to sprout thorns (end of first week) 
Further, the plants consistently had higher number and density of thorns on these plants as compared to the others.

Fig. 7 shows the control set growing. Like plants subjected to Western classical music, the control group showed no significant difference in the direction of their growth. They seemed to grow straight up and most of its growth parameters were average. The plant was healthy through the experimentation and produced pink flowers.

This systematic set of experiments show that Vedic chants and Indian classical music seem to be ideal for enhancing the growth of plants depending on the critical parameter of choice. Western classical music also had an incremental effect on the growth of plants as compared to the control group.

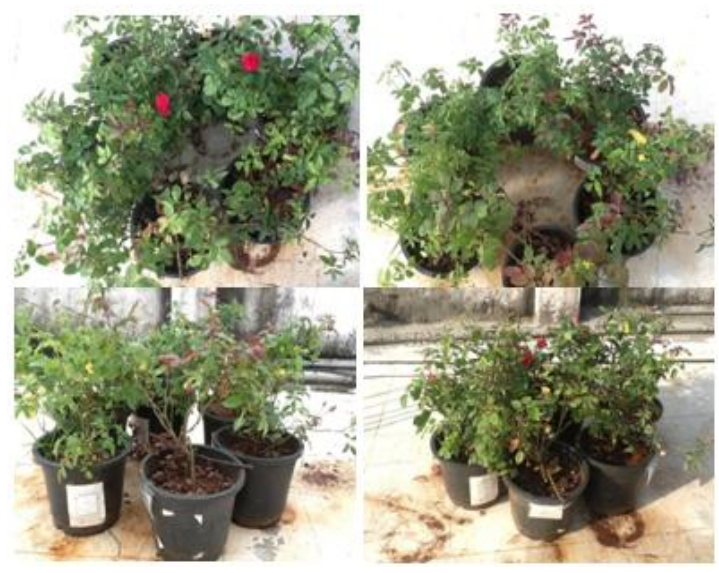

Fig. 7. The control group, not subjected to any music.

Better growth of the plants indicates that the plants are able to take up nutrients from the soil at a faster pace, are able to synthesize their proteins and the necessary components at a faster pace and the cells divide at a faster pace. Rock music on the other hand does not allow the plants to grow at their normal pace, and is clearly detrimental to plant growth. This may be due to the vibrations caused by the music. It was ensured that the volume of the music was equal for all the volumes. Since the volume was equal, the only factor that could cause the difference in the growth of the plants is the vibrations caused by the music.

\section{CONCLUSION}

It is clear that sound and music has a significant impact on the growth and germination of Rosa chinensis. Whether the impact is stimulating or detrimental depends on the type of music being player. It can also be stated that Vedic chants and Indian classical music are ideal choices while Rock music creates a havoc thereby preventing the plants from growing to their fullest. Since the shoot length, internode length, number and diameter of the flowers increase when subjected to these types of music, it could be applied in nurseries and farms to enhance the growth of the plants resulting in a better yield.

\section{ACKNOWLEDGMENT}

F. a extends her heartfelt thanks to the research team at accendere knowledge management services' for their support and guidance.

\section{REFERENCES}

[1] K. Creath and G. E. Schwartz, "Measuring effects of music, noise, and healing energy using a seed germination bioassay," J. Altern Complement Med., vol. 10, no. 1, pp. 113-122, Feb. 2004.

[2] J. Braam and R. W. Davis, "Rain-, wind-, and touch-induced expression of calmodulin and calmodulin-related genes in Arabidopsis," Cell, vol. 60, pp. 357-364, 1990.

[3] D. H. Bache and I. A. Macaskill, "Vegetation in civil and landscape engineering," in Vegetation in Civil and Landscape Engineering, London: Granada, 1984, p. 317.

[4] M. J. M. Martens and A. Michelsen "Absorption of acoustic energy by plant leaves,” J. Acoust. Soc. Am., vol. 69, pp. 303-306, 1981.

[5] M. Gagliano, "Green symphonies: a call for studies on acoustic communication in plants," Behavioral Ecology, 2012.

[6] M. S. Benford, "Implications of plant genome research to alternative therapies: A case for radiogenic metabolism in humans," J. Theoretics, vol. 4, no. 1-14, 2002.

[7] L. Dossey, "Being green: On the relationships between people and plants," Altern Ther., vol. 7, pp. 12-16, 132-140, 2001.

[8] U. Kristen, "Use of higher plants as screens for toxicity assessment," Toxicol in Vitro, vol. 11, pp. 181-191, 1997.

[9] L. Yiyaoa, B. Wanga, L. Xuefenga, D. Chuanrena, and A. Sakanishib, "Effects of sound field on the growth of Chrysanthemum callus," Colloids and Surfaces B: Biointerfaces, vol. 24, issues 3-4, pp. 321-329, April 2002.

[10] J. Yia, W. Bochua, W. Xiujuana, W. Daohonga et al., "Effect of sound wave on the metabolism of Chrysanthemum roots," Colloids and Surfaces B: Biointerfaces, vol. 29, issues 2-3, pp. 115-118, June 2003.

[11] A. Coghlan, "Good vibrations give plants excitations," New Scientist, vol. 142, issue 1927, p. 10, May 28, 1994.

[12] A. E. Lord, "Proceedings of the Technical Program," in Proc. National Noise and Vibration Control Conference, Chicago, Illinois. Acoustical Publications. Inc., 1975.

[13] C. Hicks, "Growing corn to music," Popular Mechanics, pp. 118-121, 183, May 1963.

[14] B. M. Pixton, "Plant Growth in a sound polluted environment," Botany and Plant Science Department, Brigham Young University, April 1977.

[15] Y.-C. Qina, W.-C. Leeb, Y.-C. Choib, and T.-W. Kimb, Biochemical and Physiological Changes in Plants as a Result of Different Sonic Exposures, 2003.

[16] M. E. Collins and J. E. K. Foreman, "The effect of sound on the growth of plants," Cana Acoustics, vol. 29, pp. 3-8, 2001.

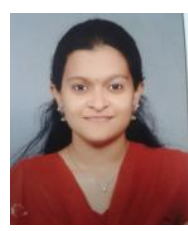

Vidya Chivukula is pursing final year of graduation in biotechnology at St. Francis College, Osmania University, Hyderabad, India. She was born in Hyderabad in 1994 and pursued her education in Hyderabad. Due to profound interest in genetics and biotechnology, she chose biotechnology, microbiology and chemistry as her subjects for under-graduation study.

She worked for 3 months on Cytogenetic and Molecular studies of Repeated abortions in the Institute of Genetics, Osmania University, Hyderabad, India

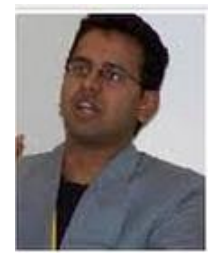

R. Shivaraman is a $\mathrm{PhD}$ and the co-founder at Accendere. He continues to spearhead the research and innovation verticals of Accendere. Having completed his masters in nanotechnology following his bachelors in computer science, Shiva derives his expertise in a broad range of topics from the time spent in top research facilities such as Carnegie Mellon University, SRM University and Bhabha Atomic Research Center.

Shiva's research interests include applications of nanotechnology for magnetic storage devices, electronics, reinforced construction components, drug delivery systems and robotics. His other areas of expertise include brain computer interfacing, earthquake detection and prevention, neural networks, artificial intelligence, genetic algorithms and non-Euclidean geometry. $\mathrm{He}$ has over 18 international journal publications, 2 international patents and over thirty international conference publications to his credit. He has been awarded several prestigious recognitions such as the Young Scientist Research Award, Board of Research in Nuclear Sciences, India and Australian Visiting Fellowship, Australian Academy of Science. 